\title{
Perfil das tenossinovites infecciosas em hospital terciário no Brasil
}

Infectious tenosynovitis profile in a tertiary hospital in Brazil

Perfil de tenosinovitis infecciosa en un hospital de tercer nivel en Brasil

Dário Rocha MARTINS ${ }^{1}$

Fernanda Ruiz de ANDRADE ${ }^{2}$

Luis Guilherme Rosifini Alves REZENDE ${ }^{2}$

Amanda Favaro CAGNOLATI ${ }^{2}$

Luiz Garcia MANDARANO-FILHO

Nilton MAZZER ${ }^{3}$

${ }^{1}$ Médico Residente em Cirurgia da Mão, Hospital das Clínicas da Faculdade de Medicina de Ribeirão Preto da Universidade de São Paulo, HC-FMRP-USP, Campus Monte Alegre, 14049-900 Ribeirão Preto - SP, Brasil

${ }^{2}$ Médico(a) Assistente do Programa de Cirurgia da Mão, Hospital das Clínicas da Faculdade de Medicina de Ribeirão Preto da Universidade de São Paulo, HC-FMRP-USP, Campus Monte Alegre, 14049-900 Ribeirão Preto - SP, Brasil

${ }^{3}$ Professor Titular e Chefe da Divisão de Cirurgia da Mão, Hospital das Clínicas da Faculdade de Medicina de Ribeirão Preto da Universidade de São Paulo, HC-FMRP-USP, Campus Monte Alegre, 14049-900 Ribeirão Preto - SP, Brasil

\section{Resumo}

A tenossinovite piogênica é uma infecção da bainha do tendão flexor do dedo que pode resultar em necrose e aderência do tendão, perda de movimento, deformidade e, em último caso, acarretar perda do membro se o tratamento não for instituído rápido e adequadamente. O objetivo desse estudo é descrever o perfil epidemiológico e bacteriológico dos pacientes com o diagnóstico de tenossinovite infecciosa em um hospital terciário. Os dados foram coletados dos prontuários dos pacientes atendidos na instituição no período de janeiro de 2019 a junho de $2020 \mathrm{com}$ o diagnóstico confirmado de tenossinovite infecciosa, e que tenham sido submetidos a tratamento clínico e cirúrgico. Os resultados encontrados foram: a prevalência de pacientes do sexo masculino, com média de 42 anos de idade, contaminados após ferimentos perfurocortantes. A bactéria mais encontrada foi Staphylococcus aureus e os resultados mais favoráveis foram nos pacientes que iniciaram o tratamento em menos de 72 horas do início dos sintomas. A suspeita clínica e o reconhecimento precoce do agente etiológico se mostraram fundamentais para minimizar as consequências potencialmente devastadoras do atraso no tratamento desta doença.

Descritores: Tenossinovite; Infecção; Bactérias.

\section{Abstract}

Pyogenic tenosynovitis is an infection of the flexor tendon sheath of the finger that can result in necrosis and tendon adhesion, loss of movement, deformity and, ultimately, lead to loss of the limb if treatment is not instituted quickly and properly. The aim of this study is to describe the epidemiological and bacteriological profile of patients diagnosed with infectious tenosynovitis in a tertiary hospital. Data were collected from the medical records of patients treated at the institution from January 2019 to June 2020 with a confirmed diagnosis of infectious tenosynovitis, and who had undergone clinical and surgical treatment. The results found were: the prevalence of male patients, with an average of 42 years of age, contaminated after sharp and cutting wounds. The most commonly found bacterium was Staphylococcus aureus and the most favorable results were in patients who started treatment less than 72 hours after the onset of symptoms. The clinical suspicion and the early recognition of the etiologic agent proved to be fundamental to minimize the potentially devastating consequences of the delay in the treatment of this disease.

Descriptors: Tenosynovitis; Infection; Bacteria.

\section{Resumen}

La tenosinovitis piógena es una infección de la vaina del tendón flexor del dedo que puede provocar necrosis y adherencia del tendón, pérdida de movimiento, deformidad y, en última instancia, llevar a la pérdida de la extremidad si el tratamiento no se instituye de forma rápida y adecuada. El objetivo de este estudio es describir el perfil epidemiológico y bacteriológico de los pacientes diagnosticados de tenosinovitis infecciosa en un hospital de tercer nivel. Se recogieron datos de las historias clínicas de los pacientes atendidos en la institución desde enero de 2019 hasta junio de 2020 con diagnóstico confirmado de tenosinovitis infecciosa, y que habían sido sometidos a tratamiento clínico y quirúrgico. Los resultados encontrados fueron: la prevalencia de pacientes del sexo masculino, con un promedio de 42 años de edad, contaminados después de heridas cortantes y cortantes. La bacteria más comúnmente encontrada fue Staphylococcus aureus y los resultados más favorables se dieron en pacientes que iniciaron el tratamiento menos de 72 horas después del inicio de los síntomas. La sospecha clínica y el reconocimiento precoz del agente etiológico resultaron fundamentales para minimizar las consecuencias potencialmente devastadoras del retraso en el tratamiento de esta enfermedad.

Descriptores: Tenosinovitis; Infecção; Bacterias.

INTRODUÇÃO

A tenossinovite piogênica é uma das formas de infecção profunda mais comum na mão. Trata-se de uma infecção no espaço fechado da bainha do tendão flexor que, devido a sua baixa oferta vascular e por ser preenchida com fluido sinovial, é um bom meio para o crescimento bacteriano ${ }^{1}$. A inoculação de bactérias no fluido sinovial causa aumento da pressão dentro da bainha, levando ao comprometimento do fluxo vascular, necrose e aderência do tendão, perda de movimento, deformidade e, em último caso, perda do membro ${ }^{2}$.

Em 1912 Allen B. Kanavel descreveu em seu estudo três sinais cardinais de tenossinovite piogênica: sensibilidade ao longo da bainha do tendão flexor, posição de descanso em flexão do dedo e dor intensa com a extensão passiva, mais acentuada na extremidade proximal ${ }^{3}$. Embora não tenha sido descrito inicialmente como um sinal cardinal, foi relatada a existência de edema fusiforme que envolve todo o dedo, que mais tarde se tornou o quarto sinal cardinal ${ }^{4}$. Os quatro sinais descritos por Kanavel, comumente conhecidos como "sinais de Kanavel", são freqüentemente usados como a principal ferramenta para o diagnóstico clínico da tenossinovite infecciosa dos flexores, visto que exames laboratoriais geralmente são inespecíficos ${ }^{5}$. 
Kennedy et $\mathrm{al}^{6}$. concluíram em seu estudo que a sensibilidade dos sinais de Kanavel variou de $91,4 \%$ a $97,1 \%$, a especificidade variou de $51,3 \%$ a $69,2 \%$ e que a probabilidade de diagnóstico de tenossinovite piogênica aumentou com o número de sinais presentes. Em contrapartida os exames laboratoriais como: níveis de velocidade de hemossedimentação (VHS) e proteína $\mathrm{C}$ reativa (PCR) não contribuíram significativamente para diferenciar a tenossinovite piogênica de outras infecções dos dedos como: paroníquia, abscesso, celulite ou outra infecção ${ }^{6}$.

O uso sistemático de ultrassonografia na emergência, quando possível, tem se mostrado uma forte aliada no diagnóstico das infecções da mão. Prunieres et al. $^{7}$ analisaram a ultrassonografia de 20 pacientes com tenossinovite piogênica e constataram um aumento de mais de $20 \%$ no diâmetro da bainha flexora perto da polia $A 2$, achados esses que contribuíram para indicação do tratamento cirúrgico ${ }^{7}$.

Espécies de Staphylococcus, incluindo $S$. Aureus resistente à meticilina, e espécies de Streptococcus são os patógenos mais comumente identificados ${ }^{8}$ embora aproximadamente um terço das culturas de feridas não amostre nenhum crescimento bacteriano e organismos gram-negativos estejam presentes em $10 \%$ dos casos. ${ }^{5} \mathrm{~A}$ propagação hematogênica para as bainhas tendinosas é menos comum e ocorre apenas em pacientes imunocomprometidos ${ }^{9}$.

A cirurgia deve ser realizada dentro de 72 horas após início dos sintomas e, quando associada ao uso precoce de antibióticos sistêmicos, apresenta resultados melhores ${ }^{10}$. Dentre as técnicas cirúrgicas utilizadas destacam-se o desbridamento com drenagem aberta e a irrigação por cateter fechado, este último resultando em melhor amplitude de movimento pós operatória em comparação com a técnica aberta ${ }^{11}$.

Com o advento dos antibióticos e o tratamento cirúrgico adequado, o risco de sequelas graves secundárias à tenossinovite infecciosa dos flexores diminuiu consideravelmente ${ }^{12}$.

Frente à rápida e devastadora evolução da tenossinovite piogênica e a escassez de literatura que descreva a prevalência dos patógenos causadores, julga-se necessário avaliar o perfil epidemiológico e bacteriológico desta patologia.

MATERIAL E MÉTODO

O projeto foi aprovado pela Comissão de
Ética em Pesquisa da Faculdade de Medicina de Ribeirão Preto da Universidade de São Paulo (FMRP-USP), através da Plataforma Brasil no dia 11 de maio de 2020 com número CAAE 31488920.1.0000.5440. Trata-se de um estudo descritivo, retrospectivo, transversal com abordagem quantitativa, realizado no Hospital das Clínicas da Faculdade de Medicina de Ribeirão Preto da Universidade de São Paulo, SP, Brasil.

Os dados foram coletados a partir da busca em prontuários dos pacientes atendidos na Unidade de Emergência do Hospital das Clínicas da Faculdade de Medicina de Ribeirão Preto da Universidade de São Paulo, entre os períodos de janeiro de 2019 a junho de 2020, com o diagnóstico clínico e ultrassonográfico confirmado de tenossinovite infecciosa. Foram identificados os prontuários através do Código Internacional de Doenças (CID-10) e /ou descrições cirúrgicas que continham como diagnóstico pré-operatório 0 termo "tenossinovite infecciosa". Estes foram avaliados através dos seguintes quesitos: gênero, idade, localização da lesão, tempo de início dos sintomas, mecanismo da lesão, agentes infecciosos encontrados nos exames de cultura, bem como tempo de internação e evolução clínica.

Incluíram-se na pesquisa indivíduos de ambos os gêneros e de todas as faixas etárias, que tenham sido atendidos na Instituição, com o diagnóstico confirmado de tenossinovite infecciosa e que tenham sido submetidos a tratamento clínico e cirúrgico com coleta de exame microbiológico confirmatório. Os critérios de exclusão abrangiam os prontuários que não continham quaisquer das seguintes informações: gênero, idade, localização da lesão, tempo de início dos sintomas, mecanismo da lesão, agentes infecciosos encontrados nos exames de cultura da lesão, tempo de internação, descrição dos procedimentos cirúrgicos e evolução clínica pós-operatória.

As informações obtidas foram incluídas em banco de dados no Programa Excel 2016 (Microsoft) e avaliadas estatisticamente. O perfil epidemiológico foi descrito por meio de porcentagens, média, desvio padrão e valores mínimo e máximo.

RESULTADOS

Foram analisados 16 pacientes; destes, 3 foram excluídos do estudo devido à falta de documentação sobre a presença dos sinais de Kanavel ou ainda pela ausência de exame confirmatório, como a cultura, permanecendo no estudo um total de 13 pacientes. 
Dos 13 pacientes analisados, três eram do gênero feminino $(23,1 \%)$ e 10 do masculino (76,9 \%). A idade média foi de 42 anos; variando de 7 a 81 anos (Desvio Padrão = $21,3)$. Oito pacientes tiveram ferimentos perfurocortantes, sendo este o mecanismo de lesão mais encontrado $(61,5 \%)$; os demais foram: 1 fratura exposta $(7,7 \%), 2$ lesões provocadas por picada de aranha (15,4\%), 1 lesão por mordida canina $(7,7 \%)$ e em 1 paciente sem etiologia definida (7,7\%). (Gráfico 1).

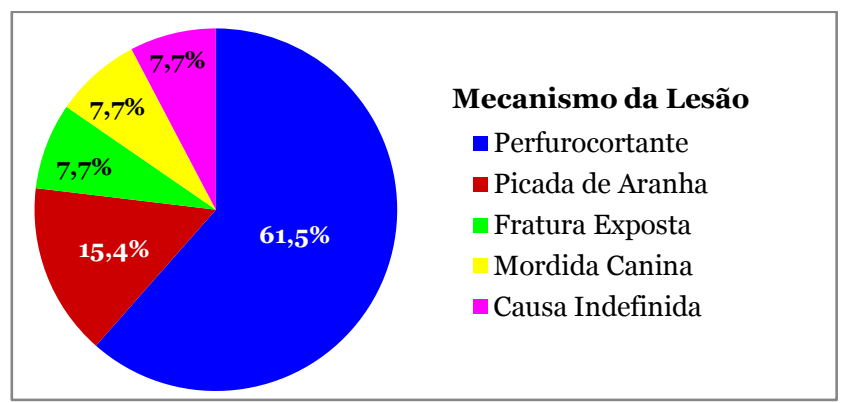

Gráfico 1: Mecanismos de lesões encontradas nos pacientes com quadro de tenossinovite piogênica dos flexores.

O local de lesão variou entre as zonas flexoras dos diversos dedos, conforme demonstrado na Figura 1, sendo o indicador direito o dedo mais frequente $(38,5 \%)$ afetado.

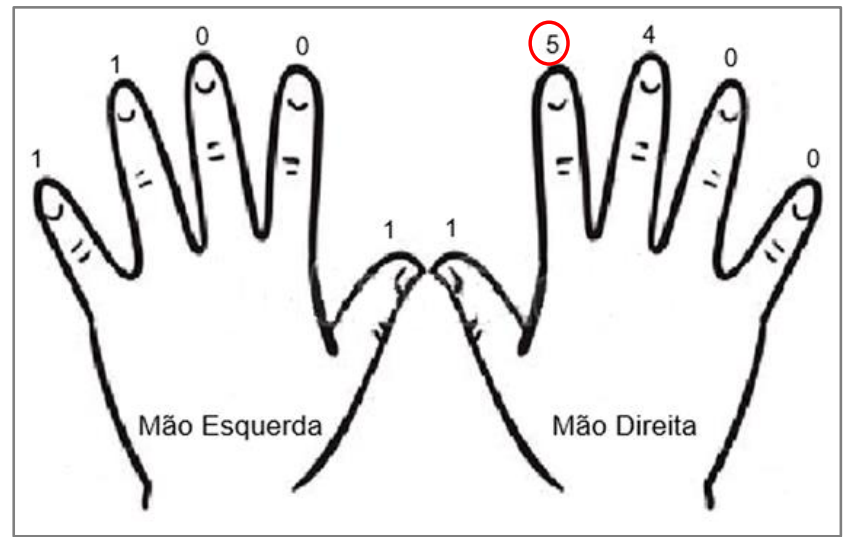

Figura 1. Frequência de acometimento dos dedos (Fonte: figura elaborada pelo autor Luis Guilherme Rosifini Alves Rezende, 2021).

O tempo médio entre o início dos sintomas e a procura por atendimento médico foi de 5 dias, variando de 1 a 20 dias (Desvio Padrão $=5,7 \%$ ) e o tempo médio de internação hospitalar foi de 12 dias, variando de 3 a 45 dias. (Tabela 1).

$O$ agente infeccioso mais encontrado nas culturas foram Staphylococcus Aureus em $60 \%$ dos casos, seguido de Pseudomonas Aeruginosa em 20\%, Klebsiella Pneumoniae em $13 \%$ e Staphylococcus Epidermidis em 7\% dos pacientes. Os antibióticos foram utilizados inicialmente de forma empírica e após o resultado das culturas, direcionados de acordo com o perfil de sensibilidade do antibiograma. A associação de ciprofloxacina com clindamicina foi utilizada em $52 \%$ dos casos, oxacilina em
$15 \%$, vancomicina em $15 \%$, sulfametoxazol com trimetoprima em $11 \%$ e gentamicina em $7 \%$ dos pacientes. (Gráfico 2).

Tabela 1. Estatísticas descritivas das variáveis numéricas

\begin{tabular}{llllll}
\hline $\mathbf{( n = 1 3 )}$ & Média & Mediana & DP & Min & Max \\
\hline $\begin{array}{l}\text { Idade } \\
\begin{array}{l}\text { Tempo de início dos } \\
\text { sintomas e atendimento }\end{array}\end{array}$ & 42,15 & 41,00 & 21,326 & 7 & 81 \\
médico & 5,31 & 2,00 & 5,736 & 1 & 20 \\
Tempo de internação & 12,77 & 10,00 & 11,741 & 3 & 45 \\
Número de cirurgias & 2,230 & 2,00 & 1,526 & 1 & 6 \\
\hline DP= desvio padrão; Min = minimo; Max = máximo & & &
\end{tabular}

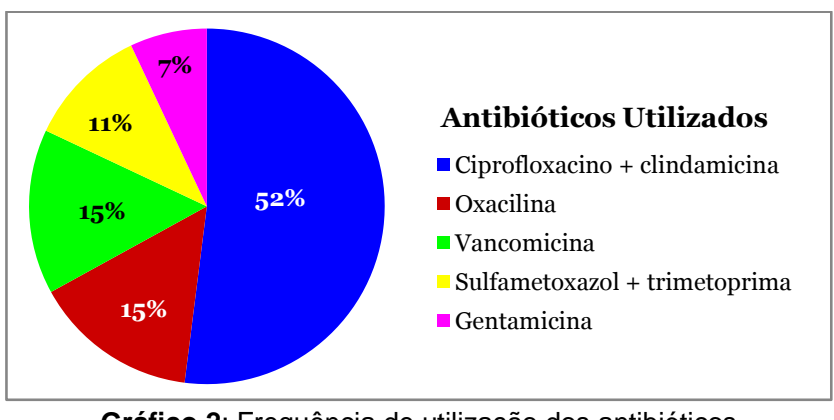

Gráfico 2: Frequência de utilização dos antibióticos

Todos os pacientes foram submetidos a tratamento cirúrgico de urgência com desbridamento e drenagem aberta. Em seis casos $(46,2 \%)$ foram necessários apenas 1 procedimento cirúrgico, pois os pacientes apresentaram boa evolução clínica; a maioria destes sofreram a intervenção cirúrgica até 3 dias do início dos sintomas. Nos casos que houve atraso na procura por atendimento médico, foram necessárias cirurgias sequenciais, a maioria desbridamentos, com limpeza mecânica copiosa e alguns evoluindo com amputação do raio digital acometido (Figura 2). O número de cirurgias variou de 1 até 6 procedimentos (Tabela 1 ).

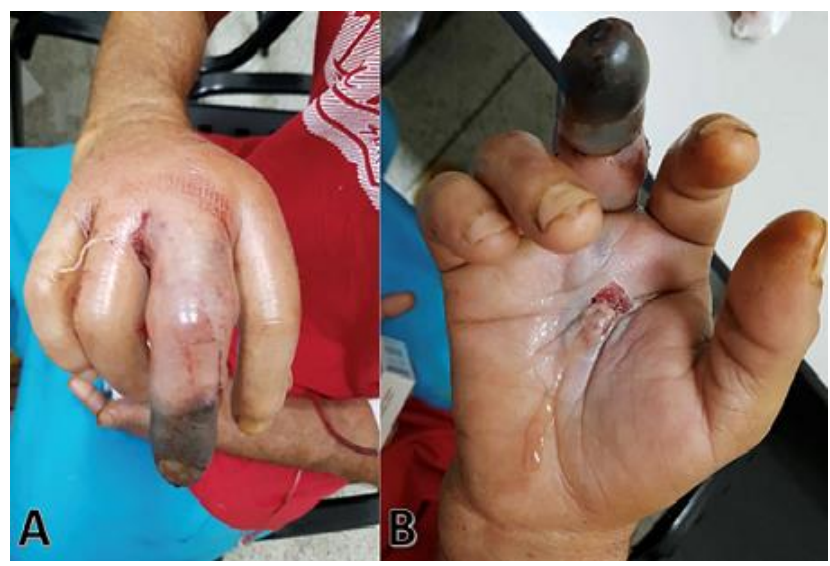

Figura 2: A e B: Tenossinovite piogênica dos flexores do terceiro quirodáctilo, com 11 dias de evolução, em paciente que procurou atendimento tardio e já apresentava necrose do dedo.

A evolução mais frequente foi a de melhora clínica em $69,2 \%$ dos casos (9 pacientes). Houve amputação do raio digital em $30,8 \%$ dos casos (4 pacientes). O agente infeccioso mais relacionado com as amputações foram S. Aureus em 75\% (3 casos) e $P$. Aeruginosa em 25\% (1 caso) (Gráfico 3). 


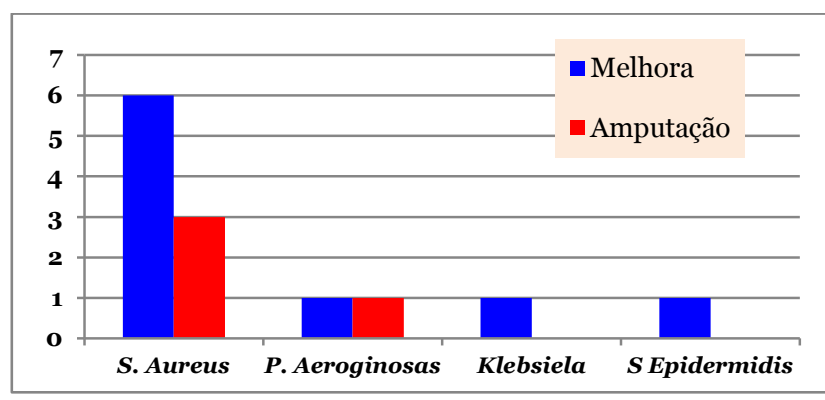

Gráfico 3: Relação Agente Etiológico X Evolução Clínica dos pacientes com tenossinovite piogênica.

DISCUSSÃO

Alguns estudos, como o de Kennedy et al. ${ }^{6}$ não encontraram diferenças em relação à idade, sexo e mecanismo de trauma dos pacientes com tenossinovite piogênica dos flexores. Entretanto este estudo demonstrou uma nítida prevalência do sexo masculino, em média aos 42 anos de idade, com ferimentos perfurocortantes provocados durante atividades manuais, o que é condizente com os encontrados por Born et al. ${ }^{13}$, que demonstraram que os ferimentos cortantes com penetração de corpos estranhos são a etiologia prevalente no desenvolvimento da doença.

O tempo médio entre o início dos sintomas e a procura por atendimento médico foi o maior definidor do resultado clínico. Os pacientes submetidos à drenagem cirúrgica em até 72 horas do início dos sintomas tiveram melhor resposta clínica e necessitaram de menor quantidade de procedimentos cirúrgicos adicionais, isto impactou em um menor tempo de internação hospitalar, permitindo a continuidade do tratamento ambulatorialmente com antibioticoterapia oral. Bolton e colaboradores, em uma revisão sistemática, relatou melhores resultados em pacientes que receberam antibióticos sistêmicos associados ao tratamento cirúrgico precoce ${ }^{14}$ e Born et al. ${ }^{13}$ descreveram um tempo médio de hospitalização de 4 dias (variando de 0 a 8 dias), demonstrando que os pacientes receberam 23 dias de antibióticos (intervalo de 8 a 47 dias) nos pacientes tratados precocemente.

Pang et al. ${ }^{15}$ analisaram alguns fatores que afetaram o prognóstico da tenossinovite piogênica em 75 pacientes submetidos a tratamento aberto ou fechado. Eles demonstraram que a idade superior a 43 anos, a existência de comorbidades associadas, a presença de secreção purulenta no subcutâneo, a isquemia digital e a presença de infecções polimicrobianas se correlacionaram negativamente com o desfecho ${ }^{15}$. Isto reforça 0 resultado encontrado neste estudo, pois quanto mais tardia foi a procura por atendimento médico pior o prognóstico, demonstrado que os pacientes que procuraram atendimento com 20 dias do início dos sintomas, apresentaram além de sinais infecciosos exuberantes como edema, purulência subcutânea, isquemia e necrose da extremidade digital, também sinais sistêmicos, como febre e queda do estado geral (Figura 2).

A evolução clínica também teve correlação com o agente etiológico encontrado. A Klebsiela pneumoniae foi encontrada em 1 paciente que evoluiu com rápida melhora clínica após o tratamento cirúrgico e o início da antibioticoterapia. Resultado semelhante foi observado no paciente infectado por $S$. Epidermidis. A P. aeruginosa foi positiva em dois pacientes com evoluções clínicas distintas: um apresentou melhora clínica satisfatória assim que iniciado o tratamento, enquanto o outro precisou ser submetido a diversos procedimentos cirúrgicos e teve indicação de amputação do dedo acometido. O S.Aureus, prevalente na maioria dos casos, mostrou pior evolução. Em $67 \%$ desses pacientes, foram necessários diversos procedimentos cirúrgicos associados ao uso do antibiótico endovenoso guiado, por meio do antibiograma. Nos outros $33 \%$, a melhora do estado clínico só foi conseguida após a amputação do dedo.

Houshian et al. $^{8}$ demostraram que espécies de Staphylococcus, incluído $S$. Aureus resistente à meticilina, e Estreptococos são os patógenos mais frequentemente identificados na tenossinovite piogênica, embora em aproximadamente um terço das culturas de feridas não apresentem crescimento de colônias bacterianas e organismos gram-negativos estejam presentes em $10 \%$ dos casos ${ }^{5}$.

A propagação hematogênica para as bainhas tendinosas é menos comum e ocorre apenas em pacientes imunocomprometidos ${ }^{9}$, o que justificaria o fato de em um dos pacientes, que apresentava HAS e DM, não ter sido identificado $o$ ponto de entrada do agente infeccioso no membro acometido.

Henton et al. ${ }^{16}$ compararam um grupo que foi submetido aos cuidados locais da ferida sem o uso de antibióticos e outro com os mesmos cuidados, acrescidos ao uso do Cefaclor ou Cefazolina intravenosa associada à penicilina $G$. $O$ ensaio foi encerrado antecipadamente em razão das altas taxas de insucesso (47\%) identificadas no grupo sem o uso de antibióticos ${ }^{16}$, reforçando a importância da antibioticoterapia precoce na melhora clínica de $69,2 \%$ dos pacientes do nosso estudo.

CONCLUSÃO

Este estudo demonstrou que o Staphylococcus Aureus foi o agente etiológico 
mais encontrado na amostra e que a população mais acometida foi caracterizada por indivíduos do sexo masculino, em idade produtiva e que apresentaram ferimentos perfurocortantes durante atividades laborais. A evolução clínica foi favorável quando se iniciou o tratamento em menos de 72 horas do início dos sintomas, demonstrando que o diagnóstico precoce e tratamento adequado são medidas fundamentais para o sucesso e salvamento do dedo.

\section{REFERÊNCIAS}

1. Osterman $M$, Draeger $R$, Stern $P$. Acute hand infections. J Hand Surg Am. 2014;39(8):162835; quiz 1635.

2. Franko OI, Abrams RA. Hand infections. Orthop Clin North Am. 2013;44(4):625-34.

3. Kanavel AB. The symptoms, signs, and diagnosis of tenosynovitis and fascial-space abscesses. In Infections of the Hand. 1st ed. Philadelphia, PA: Lea \& Febiger; 1912:201-226.

4. Kanavel AB. Infections of the Hand: A Guide to the Surgical Treatment of Acute and Chronic Suppurative Processes in the Fingers, Hand and Forearm. 7. Philadelphia, PA: Lea \& Febiger; 1939.

5. Draeger RW, Bynum DK Jr. Flexor tendon sheath infections of the hand. J Am Acad Orthop Surg. 2012;20(6):373-82.

6. Kennedy CD, Lauder AS, Pribaz JR, Kennedy SA. Differentiation Between Pyogenic Flexor Tenosynovitis and Other Finger Infections. Hand (N Y). 2017;12(6):585-90.

7. Prunières G, Igeta $Y$, Hidalgo Díaz JJ, Gouzou $S$, Facca $S$, Xavier $F$ et al. Ultrasound for the diagnosis of pyogenic flexor tenosynovitis. Hand Surg Rehabil. 2018:S24681229(18)30061-6.

8. Houshian S, Seyedipour S, Wedderkopp N. Epidemiology of bacterial hand infections. Int $\mathrm{J}$ Infect Dis. 2006;10(4):315-19.

9. Patel DB, Emmanuel NB, Stevanovic MV, Matcuk GR Jr, Gottsegen CJ, Forrester DM et al. Hand infections: anatomy, types and spread of infection, imaging findings, and treatment options. Radiographics. 2014;34(7):1968-86.

10. Giladi AM, Malay S, Chung KC. A systematic review of the management of acute pyogenic flexor tenosynovitis. J Hand Surg Eur Vol. 2015;40(7):720-28.

11. Nikkhah D, Rodrigues J, Osman K, Dejager L. Pyogenic flexor tenosynovitis: one year's experience at a UK hand unit and a review of the current literature. Hand Surg. 2012;17(2):199-203.

12. Stern PJ, Staneck JL, McDonough JJ, Neale HW, Tyler G. Established hand infections: a controlled, prospective study. J Hand Surg Am. 1983;8(5 Pt 1):553-59.
13. Born TR, Wagner ER, Kakar S. Comparison of Open Drainage Versus Closed Catheter Irrigation for Treatment of Suppurative Flexor Tenosynovitis. Hand (N Y). 2017;12(6):579-84.

14. Bolton LE, Bainbridge C. Current opinions regarding the management of pyogenic flexor tenosynovitis: a survey of Pulvertaft Hand Trauma Symposium attendees. Infection. 2019;47(2):225-31.

15. Pang HN, Teoh LC, Yam AK, Lee JY, Puhaindran ME, Tan AB. Factors affecting the prognosis of pyogenic flexor tenosynovitis. $\mathrm{J}$ Bone Joint Surg Am. 2007;89(8):1742-48.

16. Henton J, Jain A. Cochrane corner: antibiotic prophylaxis for mammalian bites (intervention review). J Hand Surg Eur Vol. 2012;37(8): 804-6.

\section{CONFLITO DE INTERESSES}

Os autores declaram não haver conflitos de interesse

\section{AUTOR PARA CORRESPONDÊNCIA}

\section{Luis Guilherme Rosifini Alves Rezende}

HC-FMRP-USP Hospital das Clínicas da

Faculdade de Medicina de Ribeirão Preto da

Universidade de São Paulo - USP

Av. Bandeirantes, 3900 -

Campus Universitário Monte Alegre

14049-900 Ribeirão Preto, SP, Brasil.

E-mail: Igrezende@usp.br 